\title{
Modifier genes in humans: strategies for identification
}

\author{
R S Houlston and IPM Tomlinson \\ Institute of Cancer Research, Sutton, Surrey, UK
}

\begin{abstract}
A number of genetic disorders exhibit inter- and intra-familial variability. Understanding the factors that control the expression of disease genes should provide insight into the fundamental disease processes and will have implications for counselling patients. Different mechanisms can account for this variability, including environmental factors, genotype-phenotype correlations and imprinting. There is also evidence that, in a number of genetic diseases, gene expression is under the control of modifier loci. In cases where the biological basis of the genetic disease is understood, any genes involved in the pathogenic process represent candidate modifier genes which can easily be evaluated. Alternatively, modifiers can be identified through approaches such as mouse models. Since modifier genes will generally be common and because of confounding environmental influences, linkage analyses in humans will generally be based upon affected or discordant sib pairs. Discordant sib pairs represent an attractive option for linkage studies, because recurrence rates are high and the reduced survival characteristics associated with severe phenotypes will make the likelihood of obtaining clinical material from two living cases difficult. Furthermore, the use of discordant siblings will select for those siblings which possess sufficient dissimilarity at the modifier locus to overcome any shared environmental influence.
\end{abstract}

Keywords: modifier loci; candidates' genes; linkage; mouse models; sib pairs

\section{Introduction}

A large number of mendelian and non-mendelian genetic disorders display considerable inter- and intrafamilial variability in phenotypic expression. There are a number of explanations to account for such variability (Table 1). ${ }^{1-31}$ In some disorders, it is clear that environmental factors (such as the effect of smoking in

Correspondence: R S H oulston, Institute of Cancer R esearch, Sutton, Surrey, SM 2 5N G, U K

R eceived 11 A ugust 1997; revised 60 ctober 1997; accepted 15 O ctober 1997 individuals with familial hypercholesterolaemia ${ }^{8}$ account for marked differences in clinical expression between individuals harbouring the same mutation. Other mendelian disorders show strong genotypephenotype correlations. $M$ utations in specific regions of the gene or specific types of mutation (e.g. mis-sense versus truncating) may be characterised by certain phenotypic features; in the BRCA 2 gene, for example, mutations at the $3^{\prime}$ end of the gene are characterised by an increased risk of ovarian cancer compared with mutations in the $5^{1}$ region. ${ }^{4} \mathrm{~A}$ Iternatively, genotypephenotype correlation can result from gene modification, such as in the case of trinucleotide repeat 
expansion causing myotonic dystrophy and Huntington's chorea. ${ }^{12}$ For $\mathrm{X}$-linked disorders, differences in $X$-inactivation between carriers are another specific mechanism for phenotypic variability.

In recent years it has also been recognised that the route of inheritance of a gene, that is the parental origin, can influence its phenotypic effects and tissue expression. Non-disjunction during meiotic segregation in translocation heterozygotes can lead to transmission from one parent only, resulting in uniparental disomy or monosomy. For certain loci, uniparental inheritance has a detrimental effect, the nature and severity of which depends on whether the inheritance is maternal or paternal. Two of the most convincing examples of such imprinting in human disease are the A ngelman and Prader-Willi syndromes, which have different phenotypes but both involve deletions of $15 q 11-13 .{ }^{10} \mathrm{In}$

Table 1 Mechanisms for the modification of genetic diseases

\begin{tabular}{|c|c|}
\hline M echanism & Example \\
\hline $\begin{array}{l}\text { G enotype-phenotype } \\
\text { correlations }\end{array}$ & $\begin{array}{l}\text { i. G ene expansion } \\
\text { H untingdon's disease }{ }^{1} \\
\text { M yotonic dystrophy² } \\
\text { ii. M utation site } \\
\text { A denomatous polyposis coli3 } \\
\text { BR CA } 2^{4}\end{array}$ \\
\hline Skewed $\mathrm{X}$ inactivation & $\begin{array}{l}\text { A cardi syndrome } \\
\text { Wiskott A Idrich } 6 \\
\text { L esch N yhan }\end{array}$ \\
\hline E nvironmental factors & $\begin{array}{l}\text { Familial hypercholesterolaemia8 } \\
\text { Phenylketonuria9 }\end{array}$ \\
\hline I mprinting & $\begin{array}{l}\text { Prader-Willi syndrome } 10 \\
\text { A ngelman syndrome10 } \\
\text { A lbright's osteodystrophy } 11 \\
\text { H untington's disease12 } \\
\text { M yotonic dystrophy } 12 \\
\text { N eurofibromatosis type } 1^{12} \\
\text { N eurofibromatosis type } 2^{12} \\
\text { R etinoblastoma13 } \\
\text { Spinocerebellar ataxia type } 1^{12} \\
\text { A topy14 } \\
\text { N eural tube defects15 } \\
\text { D iabetes } \\
\text { A dult polycystic disease } \\
17\end{array}$ \\
\hline M osaicism & $\begin{array}{l}\text { H ypohidrotic ectodermal dysplasia } 18 \\
\text { M achado J oseph disease } 19\end{array}$ \\
\hline M odifying gene & $\begin{array}{l}\text { Familial hypercholesterolaemia20 } \\
\text { BRCA } 121 \\
\text { Familial polyposis coli22 } \\
\text { A Ipha thalassaemia23, } 24 \\
\text { N eurofibromatosis type } 125 \\
\text { Fragile X } 26 \\
\text { Sickle cell anaemia27 } \\
\text { ID D M } 28 \\
\text { G raft-versus-host disease } 29-31\end{array}$ \\
\hline
\end{tabular}

addition, distortion of segregation ratios, associated with diabetes, ${ }^{16}$ neural tube defects ${ }^{15}$ and atopic pedigrees $^{14}$ may also reflect a parent of origin effect.

It is, however, important to distinguish between interand intra-familial variability in ascribing possible mechanisms to account for phenotypic variability in disease gene carriers. Differences in environmental factors and different mutations can easily be seen to underlie a proportion of inter-familial manifestations. However, intra-familial variability, especially in siblings, cannot intuitively be so readily accounted for by these types of mechanisms. There is now increasing evidence that the manifestations of many genetic disorders are influenced by so-called 'modifying' genes distinct from the disease locus. For some conditions, there is indirect support for the notion of modifying genes from studies undertaken in mice. In general, mice with specific genetic backgrounds often express the same genetic disease very differently. Specific modifying loci have also been identified. For example, two or more modifiers of the phenotype of the Multiple intestinal neoplasia ( $M$ in) mouse model of FAP are known to exist. ${ }^{32,33}$ One (M om-1) maps to equivalent of human 1p35-p36 and a candidate for M om-1 is the secretory phospholipase A 2 gene. $^{32,33}$ In a number of human disorders, moreover, there is direct evidence for modifying loci (for example in the case of BRCA 1 and $\mathrm{H}-$ ras. $^{20}$ In other cases, the evidence is indirect: for example, only one in three individuals with insulin dependent diabetes mellitus (ID D M ) develops diabetic nephropathy, ${ }^{34}$ although the relative risk of this complication is increased two-fold in relatives of IDDM patients with nephropathy. ${ }^{28}$ Thus, it is likely that a modifying locus is acting if there is intra-familial variability in phenotype in the absence of known or probable environmental factors, and/or there is increased familial risk of a specific phenotypic feature within families.

\section{What is a Modifier Locus?}

For a Mendelian disease, a modifying locus can be defined as inherited genetic variation (distinct from the disease locus) that leads to a quantitative or qualitative difference in any aspect of the disease phenotype. The definition thus includes genes that lead to non-penetrance of the disease allele. For complex genetic diseases, the definition of a modifying locus is the same, although genes which contribute to the risk of disease are better classed as disease-predisposing loci, rather than as modifiers, even though they may have some additional effect on the phenotype. Thus, modifiers of complex disease do not have a qualitative effect on the 
basic disease phenotype, although they have qualitative effects on sub-phenotypes, such as the development of nephropathy in IDDM.

Modifying genes can act in many different ways. The major possibilities are as follows:

(i) cell-autonomous, tissue specific or systemic action;

(ii) qualitative or quantitative effects, both at the level of the protein and the disease phenotype;

(iii) specific action on disease pathways, or nonspecific action;

(iv) direct action, or requiring activation through somatic mutation or a specific environment.

\section{Methods}

\section{Evaluation and Identification of Modifier Genes}

Where there is an understanding of the pathological basis of the disease, other genes involved in the disease process provide candidates for modifier loci. The possible participation of such loci can easily be examined by determining their relative frequency according to disease severity or some other clinical variable. Familial hypercholesterolaemia, for example, is caused by a defective $L D L$ receptor gene. It is likely that variation in genes for other elements of the lipoprotein pathway, such as A po-a or A po-E which are ligands for the receptor, leads to phenotypic variation in familial hypercholesterolaemia. ${ }^{20}$ The possible role and effect of variation in any putative candidate modifier gene can be determined either using a case-control approach or, where parental DNAs are available, the transmission disequilibrium test. ${ }^{35}$

It is clear, however, that for most genetic diseases where the underlying basis of the disorder has not been established, this approach will not be viable. Identification of modifier loci will generally depend upon linkage. This can be based on mouse models, generally utilising an intercross between strains with discordant disease features, followed by a backcross or production of $F_{2}$ hybrids which can be used for linkage analysis. The $M$ in mouse provides a model for familial colon cancer: it carries a mutant mouse A PC gene and develops many intestinal adenomas. Using an intercross/backcross approach, a modifier locus M om-1 (M odifier of M in- 1 ) was mapped to mouse chromosome 14, syntenic with human chromosome $1 p 35-p 36 .{ }^{33}$ Variation at this locus accounted for about $50 \%$ of the observed genetic variation in tumour number. Subsequently, the secretory phospholipase A 2 locus was suggested as a candidate for M om-1. A Ithough experiments suggested an effect of a locus on 1p35-p36 on human FA P, no variation was identified in human secretory phospholipase A 2 (PLA 2G 2A) that could account for this effect. In other cases, although the sites of modifier loci have been determined, no candidate genes have been identified. M ohlke et al analysed a cross between RIIIS/J and CA SA /Rk, two strains of mice that exhibit a 20-fold difference in plasma von Willebrand factor (VWF) levels. ${ }^{36}$ DNA samples from $F_{2}$ progeny with very high or very low plasma vWF levels were pooled and genotyped at 41 markers throughout the genome. A locus accounting for $63 \%$ of the total variance in vWF level was mapped to distal mouse chromosome 11. U sing survival as a phenotype, R ozmahel et al showed that a major modifier locus of the cystic fibrosis transmembrane conductance regulator maps near the centromere of mouse chromosome $7 .^{37}$ lakoubova et al found evidence for modifiers of mouse juvenile polycystic kidney disease on chromosomes 10 and $1 .^{38}$

Mouse models provide certain advantages, such as the availability of large numbers of experimental matings and the ability to minimise variation in the environmental influences on disease. There are, however, potential problems with mouse models. First, in $M$ endelian disease, mouse and human disease phenotypes are often dissimilar, even if the underlying mutation is the same. Second, different genetic and cellular pathways may underlie apparently similar diseases in mouse and humans. Third, selective pressures and chance effects mean that the type and extent of genetic variation varies between different strains of laboratory mice and between mice and humans; hence, there may be no genetic variation at some potential modifying loci in one species whilst there is variation in another species. Fourth, the inbred nature of the laboratory mouse means that as a result of linkage disequilibrium, it is often difficult to identify modifier genes once they have been mapped; creation of a 'knockout' mouse may be necessary to test the effects of any putative modifier.

$O$ wing to the lack of good candidate genes and potential problems with mouse models, the identification of many modifier genes will often primarily be based on linkage analysis in human pedigrees. $M$ apping modifier genes is, however, likely to be much less straightforward than identifying the primary disease 
gene loci. Detection of linkage will probably depend upon the analysis of sibling pairs for a number of reasons. Firstly, although the sibling recurrence risk for a specific manifestation of the disease may be high, the overall risk will also be high; thus, relative risks will be at most modest, making the value of more distant relatives poor. Secondly, the population frequency of a modifier allele has to be high in order to co-segregate with the primary disease; thus, new modifying alleles are likely to derive from pedigree founders and the analysis of distant relatives will therefore provide no information on linkage or will be against linkage. Thirdly, if a particular disease manifestation is also influenced by environmental factors, affected individuals outside the nuclear family are obviously less attractive for study. Finally, many phenotypic variables are highly age-dependent and, although adjustment can be made for this, siblings are generally of similar ages.

\section{Sibling Pair Methods for Identifying Modifier Genes}

Linkage studies utilising sibling pairs can be based either on the analysis of affected sib pairs (A SPs), or on discordant sib pairs (DSPs). For a linked marker, the A SP and DSP allele probabilities of sharing 0,1 or 2 alleles IBD $\left(Z_{i}\right.$ and $Y_{i}$ respectively) will deviate in opposite directions from the null expectation $\left(\alpha_{i}{ }^{39,40}\right.$

In a sib-pair study, the power to demonstrate linkage depends upon the deviation of allele sharing between siblings from the probability of identity by descent (IBD) under the null expectation. This depends on the contribution that the locus makes to the genetic variation in the trait and is generally measured in terms of the increased risk to relatives of affected probands compared with the population risk (A ppendix 1). Compared with A SPs, DSPs are generally not the most powerful approach to mapping disease genes characterised by low recurrence risks. However, to detect modifying loci, DSPs can be superior to A SPs, both in terms of power and because discordant sibs are a priori more likely to be segregating a modifying allele.

In order to compare the power of the two sib-pair methods in the identification of modifier loci, consider a hypothetical situation in which the a specific qualitative clinical feature of a genetic disease is present in $40 \%$ of cases and is wholly due to the co-inheritance of a modifier gene. If the modifier phenotype were dominantly inherited, the offspring recurrence risk will be $66 \%$ and the sibling recurrence risk $68 \%$. A Iternatively if the gene were to act recessively, then the offspring risk would be $63 \%$ and the sibling recurrence risk would be $66 \%$. Figure 1 shows the power of DSPs and A SPs to demonstrate a lod score of 3.0 for varying numbers of sibling pairs if the gene were to act recessively. Because both the offspring and sibling recurrence risks are similar for both gene models the power to demonstrate linkage under the dominant model will be almost identical. Figure 1 clearly shows the DSP approach would be far superior to the A SP.

The power to detect linkage depends on the degree of deviation that the sharing IBD has from its null expectation. This depends on the contribution that the locus makes to the genetic variation in the trait and is generally measured in terms of the increased risk to relatives of affected probands compared with the population risk. However, the sibling recurrence risk is the most important parameter determining the relative efficiency of DSPs and ASPs. Figure 2 shows the absolute deviations of $Z_{0}$ and $Y_{0}$ from $\alpha_{0}$ for A SPs and DSPs for a range of sibling recurrence risks under dominant and recessive modes of inheritance for a modifier gene. In both cases, when the sibling recurrence risk is low, there will be much less power in using DSPs than A SPs; when the sibling recurrence risk is high, however, the optimal method for detecting linkage will be by use of DSPs. This is because the magnitude of the deviations for DSPs compared with A SPs is given by $K_{s} /\left(1-K_{s}\right)$ and will be less than unity provided $\mathrm{K}_{\mathrm{s}}<0.5 .^{39}$

The inevitability of reduced penetrance leads to a reduced power to detect linkage. Figure 3 shows the

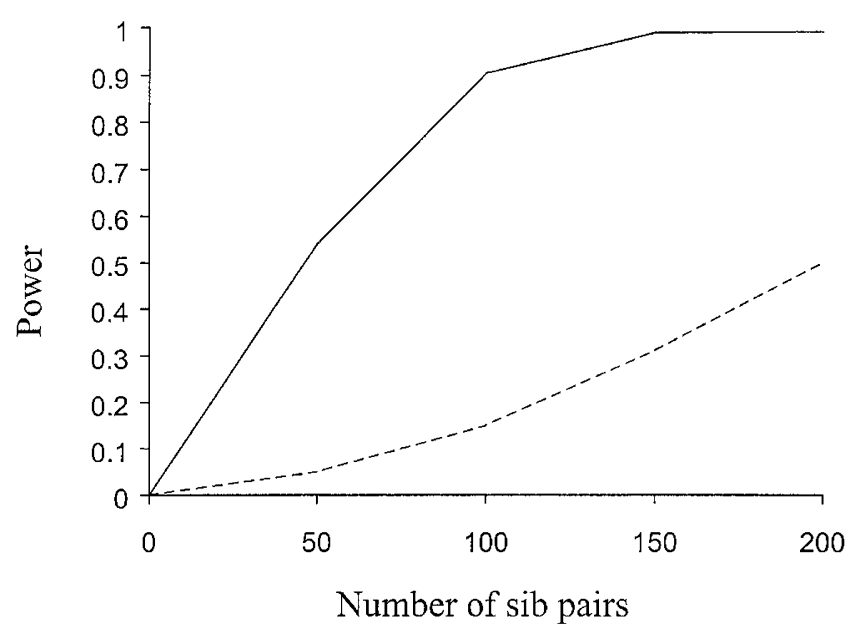

Figure 1 Power comparison of ASPS (- - -) and DSPS $(---)$ to demonstrate a lod score of 3.0 assuming average marker spacing of $10 \mathrm{cM}$, infinite number of marker alleles and availability of parental data (for determination of power see A ppendix 2) 
effect of incomplete penetrance on the absolute deviations from the null expectation of zero sharing under dominant and recessive models. Provided recurrence risk is high, D SPs still offer the most efficient method of demonstrating linkage.

The prospects for detecting linkage also depend upon the number of loci involved. Two or more genes can act either multiplicitively (i.e. the penetrance of the disease is the product of the penetrances contributed by two or more loci) or additively (i.e. the penetrance of the disease is represented by the sum of the penetrances contributed by two or more loci). $\mathrm{R} \mathrm{isch}^{40}$ showed that the A SP probabilities for a multiplicative model are identical to a single-locus formula. Hence, the DSP probabilities will be specified accordingly. For an additive model or if genetic heterogeneity exists, the situation is quite different, and for both A SPs and D SPs the power to detect linkage depends on the total relative risk and not solely on the relative risk attributable to the one locus. The existence of multiple contributing loci obviously greatly reduces the power of

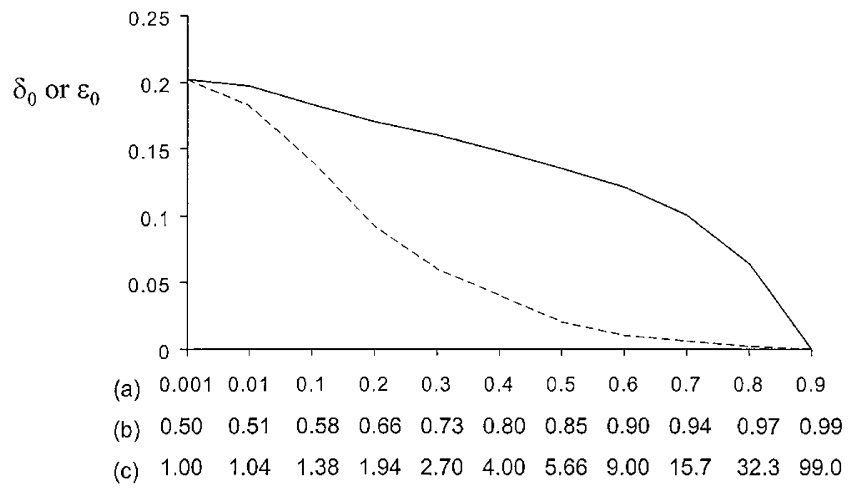

(I) dominant gene

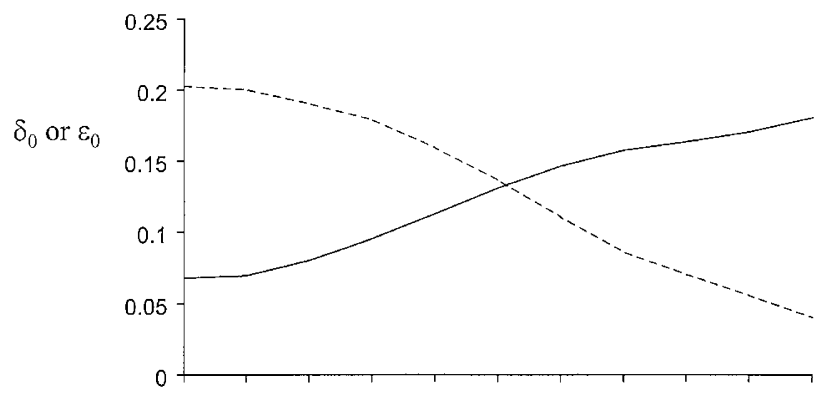

(a) $\begin{array}{lllllllllll}0.001 & 0.01 & 0.1 & 0.2 & 0.3 & 0.4 & 0.5 & 0.6 & 0.7 & 0.8 & 0.9\end{array}$

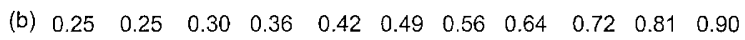

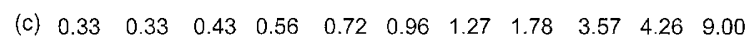

(II) recessivet gene

Figure 2 E ffect of (a) frequency of disease gene (b) sibling recurrence risk and (c) $K_{s} /\left(1-K_{s}\right)$ on deviations of $Z_{0}$ and $Y_{0}$ from $\alpha_{0}\left(\delta_{\mathrm{i}}\right.$ and $\varepsilon_{\mathrm{i}}$ respectively) (i) dominant gene A SP - - - DSP --- (ii) recessive gene A SP - - - - DSP --- detecting a given locus, but the deterioration of power is usually greater for an additive model than for a multiplicative. The effect of genetic heterogeneity on the comparative power of the A SPs and DSPs is also shown. A gain, the magnitude of deviations for DSPS compared with A SPs is given by $K_{s}\left(1-K_{s}\right)$, making the DSPs a more favourable approach to mapping modifiers if the recurrence risk is high (A ppendix 1 ).

If some of the disease features can be ascribed to phenocopies, D SPs are less likely to be discordant and A SPs less likely to be concordant at a marker which is linked to the trait locus, leading to a reduction in power for both approaches.

Irrespective of the relative merits of DSPs versus A SPs the power of any proposed study for detecting a modifier gene will depend upon the absolute deviations of $Z_{i}$ or $Y_{i}$ from the null expectations, and in many cases where the overall frequency of the condition is high the numbers of cases required to have any hope of

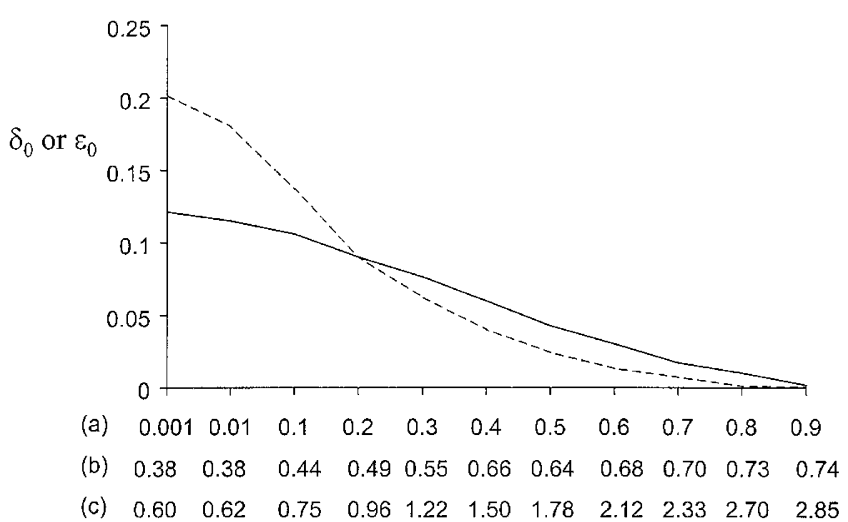

(I) dominant gene with $75 \%$ penetrance

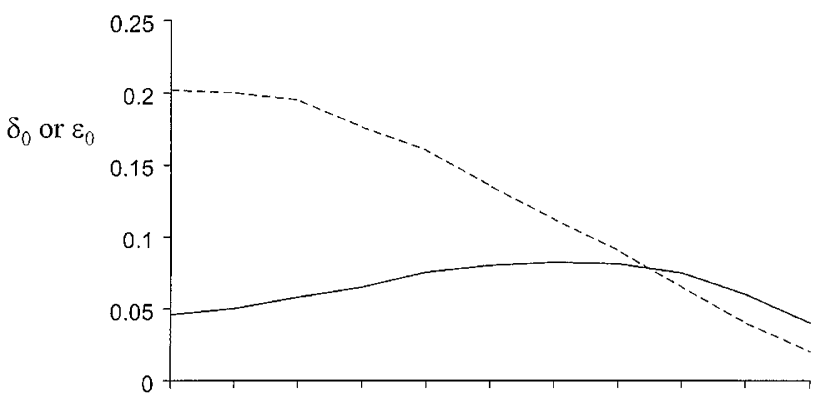

(a) $\begin{array}{lllllllllll}0.001 & 0.01 & 0.1 & 0.2 & 0.3 & 0.4 & 0.5 & 0.6 & 0.7 & 0.8 & 0.9\end{array}$

(b) $\begin{array}{lllllllllll}0.19 & 0.19 & 0.23 & 0.27 & 0.32 & 0.37 & 0.42 & 0.48 & 0.54 & 0.61 & 0.67\end{array}$

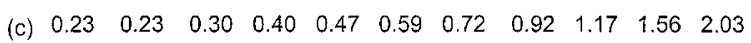

(II) recessivet gene with $75 \%$ penetrance

Figure 3 E ffect of (a) frequency of disease gene (b) sibling recurrence risk and (c) $K_{s} /\left(1-K_{s}\right)$ on deviations of $Z_{0}$ and $Y_{0}$ from $\alpha_{0}$ ( ${ }^{\circ}$ and $\varepsilon_{i}$ respectively) (i) dominant gene with $75 \%$ penetrance ASP - - - - DSP --- (ii) recessive gene with $75 \%$ penetrance A SP - - - - DSP --- 
detecting linkage will be prohibitively large. For example if $27 \%$ of individuals carry and manifest the effects of the modifier allele and the sibling recurrence risk is $50 \%, 200$ sibling pairs will provide $90 \%$ power to demonstrate linkage using either A SPs or D SPs; but if $56 \%$ of individuals carry and manifest the modifier allele and the sibling recurrence risk is $64 \%, 500$ siblings pairs will provide only $75 \%$ power to demonstrate linkage using DSPs and only $13 \%$ using A SPs.

\section{Alternative Strategies to Identify Modifier Genes}

To identify modifier genes in most cases will be reliant on either ASPS or DSPs, although some novel approaches can be applied to certain situations, for instance if a modifying gene acts as a tumour suppressor. A ccording to the two-hit hypothesis, both copies of a tumour suppressor gene have to be abnormal for tumour development. Patients with an inherited predisposition carry a defective allele of a tumour suppressor gene in the germ line. In tumours from these patients, the second allele is inactivated by a somatic event, such as a deletion. This can be assessed by loss of heterozygosity ( $\mathrm{LOH})$ studies. $\mathrm{LOH}$ in tumours can be treated as an additional observation on disease phenotype and used to enhance the power to detect linkage. ${ }^{41}$ The use of $\mathrm{LOH}$ can be extended and used to map predisposition loci directly and it is therefore conceivable that this approach could be adopted for the detection of modifying loci in certain $M$ endelian conditions characterised by variable tumour expression, such as macrocephaly in neurofibromatosis or desmoids in FA P. It is, however, arguable that any modifier locus that undergoes allele loss will also undergo somatic mutation plus allele loss in some tumours which do not have the modifying allele in the germ line. Thus far, study of tumour suppressor genes has failed to identify any loci which are good candidates for modifying loci in humans.

A nother slightly different approach to linkage could be applied to the situation of graft-versus-host ( $\mathrm{G} \mathrm{VH}$ ) reaction. The greatest determinant of $\mathrm{GVH}$ reaction in tissue transplants is the human leukocyte antigen (HLA ) system. It is, however, recognised that even with $\mathrm{HLA}$ matching between siblings, patients can have very different outcomes in terms of GVH reaction. A proportion of transplanted individuals requires little immunosuppression, and a proportion experiences GVH reaction despite immunosuppression, thus suggesting that other genes influence this process. It is very probable that a recipient of a transplant with no sequelae will be more likely to be concordant with his or her donor sibling at the modifier locus as compared to those with a poor course. M inor histocompatibility antigens have been shown to segregate in families ${ }^{30}$ and immunodominant minor histocompatibility antigens identified in humans and the mouse. ${ }^{28,29}$ Taking sibling pairs from both ends of the clinical spectrum offers an opportunity to undertake a combined discordant and concordant type of analysis in order to identify further modifier loci.

\section{Discussion}

Understanding the factors that control phenotypic expression in genetic diseases is important for understanding the disease process and for patient counselling. The considerable inter- and intra-familial variability in a number of genetic diseases is likely to result from the action of modifier genes. These modifier loci may provide targets for therapy that are more useful than the genes primarily involved in causing the disease. O ne approach to locate modifier genes has been to use mouse models. However, this indirect approach is unlikely to obviate the need to undertake linkage searches to identify novel modifier genes in humans. Where there is an understanding of the biological basis of the disease, other genes involved in the disease process can be evaluated as candidates for disease modification. However, it is likely that for the foreseeable future the identification of modifier genes will depend principally upon linkage analysis, either in the form of A SPs or DSPs. Extended pedigrees are unlikely to be useful, essentially because of the risk of phenocopies and the probable high frequency of modifier alleles in the general population, and hence in pedigree founders. In contrast to primary mapping of disease genes where ASPs are generally preferable, DSPs represent an attractive option, because of the high recurrence rates seen, and also because of the reduced survival characteristics associated with severe phenotypes which make the likelihood of ascertaining and obtaining clinical material from living cases less likely. Furthermore, as has been pointed out by others, ${ }^{42}$ concordant siblings include not only pairs sharing at the locus of interest, but also those in whom the features are phenocopies due to common environment; in contrast discordant siblings will select for those siblings which possess sufficient dissimilarity at the locus to the any environmental influence. We therefore favour the use of DSPs for identifying modifying loci in 
both qualitative and quantitative human genetic diseases.

\section{References}

1 A ndrew SE et al: The relationship between trinucleotide (CA G ) repeat length and clinical features of $\mathrm{H}$ untington's disease. Nat G enet 1993; 4: 398-403.

$2 \mathrm{H}$ arley $\mathrm{HG}$ et al: Expansion of an unstable DNA region and phenotypic variation in myotonic dystrophy. $\mathrm{N}$ ature 1992; 355: 545-547.

3 Cama A et al: Multiplex PCR analysis and genotype phenotype correlations of frequent A PC mutations. $\mathrm{H}$ um M utat 1995; 5: 144-152.

$4 \mathrm{G}$ ayther SA et al: Variation of risks of breast and ovarian cancer associated with different germline mutations of the BRCA 2 gene. N at G enet 1997; 15: 103-105.

5 Neidich JA et al: Heterogeneity of clinical severity and molecular lesions in A icardi syndrome. J Pediatr 1990; 116: 911-917.

6 De Saint Basile $G$ et al: $X$-linked thrombocytopenia and Wiskott $A$ Idrich syndrome: similar regional assignment but distinct $X$ inactivation pattern in carriers. Ann Hematol 1991; 63: 107-110.

$7 \mathrm{~A}$ ral B et al: Novel nonsense mutation in the hypoxanthine guanine phosphoribosyltransferase gene and nonrandom $X$ inactivation causing L esch $N$ yhan syndrome in a female patient. H um M utat 1996; 7: 52-58.

8 B eaumont $V$, Jacotot B, B eaumont J L : I schaemic disease in men and women with familial hypercholesterolaemia and xanthomatosis. A comparative study of genetic and environmental factors in 274 heterozygous cases. A therosclerosis 1976; 24: 441-450.

9 Schulz B, B remer HJ : N utrient intake and food consumption of adolescents and young adults with phenylketonuria. A cta Paediatr 1995; 84: 743-748.

10 B uiting $\mathrm{K}$ et al: Inherited microdeletions in the A ngelman and Prader-Willi syndromes define an imprinting centre on human chromosome. Nat G enet 1995; 9: 395-400.

11 Wilson LC et al: Parental origin of $G s$ alpha gene mutations in A Ibright's hereditary osteodystrophy. J Med Genet 1994; 31: 357-359.

12 Chatkupt S, A ntonowicz M, Johnson WG: Parents do matter: genomic imprinting and parental sex effects in neurological disorders. J Neurol Sci 1995; 130: 1-10.

13 L each RJ et al: Preferential retention of paternal alleles in human retinoblastoma: evidence for genomic imprinting. Cell Growth Differ 1990; 1: 401-406.

14 Cookson WO et al: Maternal inheritance of atopic IgE responsiveness on chromosome IIg. L ancet 1992; 340: 381-384.

15 Byrne J et al: Multigeneration maternal transmission in I talian families with neural tube defects. A m J M ed G enet 1996; 66: 303-310.

$16 \mathrm{M}$ argaritte Jeannin $\mathrm{P}$, Clerget Darpoux $F, H$ ors J, Deschamps 1: Testing parental imprinting in insulin dependent diabetes mellitus by the marker association segregation chi 2 method. Am J Hum Genet 1995; 56: 1080-1087.
17 Zerres K, Rudnik Schoneborn S, Deget F: Childhood onset autosomal dominant polycystic kidney disease in sibs: clinical picture and recurrence risk. J Med Genet 1993; 30: 583-588.

18 Bartstra HL et al: Mosaic expression of hypohidrotic ectodermal dysplasia in an isolated affected female child. A rch Dermatol 1994; 130: 1421-4.

19 Tanaka $F$ et al: Differential pattern in tissue specific somatic mosaicism of expanded CA G trinucleotide repeat in dentatorubral pallidoluysian atrophy, M achado Joseph disease, and $\mathrm{X}$-linked recessive spinal and bulbar muscular atrophy. J Neurol Sci 1996; 135: 43-50.

20 Lindahl G, M ailly F, H umphries S, Seed M : A polipoprotein $E$ phenotype and ipoprotein (a) in familial hypercholesterolaemia: implication for lipoprotein (a) metabolism. Clin Investig 1994; 72: 631-638.

21 Phelan CM et al: O varian cancer risk in B RCA 1 carriers is modified by the HRAS1 variable number of tandem repeat (VNTR) locus. N at G enet 1996; 12: 309-311.

22 Tomlinson IPM et al: A modifying locus for familial adenomatous polyposis may be present on chromosome 1p35-p36. J M ed G enet 1996; 33: 268-273.

23 Kulozik AE: Beta thalassemia: molecular pathogenesis and clinical variability. K lin Padiatr 1991; 203: 276-283.

24 Cao A, Murru S: Molecular pathology and detection of beta thalassemias. Prog Clin Biol Res 1989; 309: 3-11.

25 Easton DF, Ponder MA, Huson SM, Ponder BA: A n analysis of variation in expression of neurofibromatosis (NF) type 1 (NF1): evidence for modifying genes. A m J H um G enet 1993; 53: 305-313.

26 Steinbach P: M ental impairment in $M$ artin B ell syndrome is probably determined by interaction of several genes: simple explanation of phenotypic differences between unaffected and affected males with the same $X$ chromosome. $\mathrm{H}$ um $\mathrm{G}$ enet 1986; 72: 248-252.

$27 \mathrm{Embury} \mathrm{SH}$ : A Ipha thalassemia. A modifier of sickle cell disease. A nn N Y A cad Sci 1989; 565: 213-221.

28 Quinn M, A ngelico MC, Warram JH, Krolewski A S: Familial factors determine the development of diabetic nephropathy in patients with IDDM. Diabetologia 1996; 39: $940-945$.

29 den $\mathrm{H}$ aan JM et al: Identification of a graft-versus-host disease associated human minor histocompatibility antigen. Science 1995; 268: 1476-1480.

30 Perreault $C$ et al: Identification of an immunodominant mouse minor histocompatibility antigen ( $\mathrm{MiHA}$ ). $\mathrm{T}$ cell response to a single dominant $\mathrm{M} \mathrm{iH} \mathrm{A}$ causes graft-versushost disease. J Clin I nvest 1996; 98: 622-628.

31 Nishimura $M$ et al: Family segregation analysis of inheritance of human minor histocompatibility antigen. Cell Immunol 1995; 163: 319-322.

32 M oser A R et al: A pcM in: a mouse model for intestinal and mammary tumorigenesis. Eur J Cancer 1995; 31A : 1061-1064.

33 Dietrich WF et al: Genetic identification of Mom-1, a major modifier locus affecting $M$ in-induced intestinal neoplasia in the mouse. Cell 1993; 75: 631-639.

$34 \mathrm{~K}$ rolewski AS et al: The changing natural history of nephropathy in type I diabetes. A m J Med 1985; 78: 785-794.

35 E wens WJ, Spielman R S: The transmission/disequilibrium test: history, subdivision, and admixture. A m J H um G enet 1995; 57: 556-564. 
36 Mohlke $K L$ et al: A novel modifier gene for plasma von Willebrand factor level maps to distal mouse chromosome 11. Proc N atl A cad Sci USA 1996; 93: 15352-15327.

37 R ozmahel $R$ et al: M odulation of disease severity in cystic fibrosis transmembrane conductance regulator-deficient mice by a secondary genetic factor. $\mathrm{N}$ at $\mathrm{G}$ enet 1996; 12: 280-287.

38 lakoubova OA, D ushkin H, B eier D R : L ocalization of a murine recessive polycystic kidney disease mutation and modifying loci that affect disease severity. G enomics 1995; 26: 107-114.

$39 \mathrm{R}$ isch $\mathrm{N}$ : Linkage strategies for genetically complex traits. I. Multilocus models. Am J Hum Genet 1990; 46: 222-228.

$40 \mathrm{R}$ isch $\mathrm{N}$ : Linkage strategies for genetically complex traits. II. The power of affected relative pairs. A m J Hum G enet 1990; 46: 229-241.

41 Teare MD, R ohde K, Santibanez Koref MF: The use of loss of constitutional heterozygosity data to ascertain the location of predisposing genes in cancer families. J M ed G enet 1994; 31: 448-52.

42 R ogus JJ, K rolewski A S: U sing discordant sib pairs to map loci for qualitative traits with high sibling recurrence risk. A m J H um G enet 1996; 59: 1579-81.

\section{Appendix 1: Allele Sharing Probabilities of ASPs and DSPs}

$\mathrm{R}$ isch has previously derived the allele sharing probabilities of ASPS and DSPS. ${ }^{39,40}$ A dopting the same nomenclature:

$\alpha_{i}=P($ sibs share marker alleles IBD )

$Z_{i}=P$ (sibs share $\mathrm{i}$ marker alleles IBD|A SP)

$\mathrm{Y}_{\mathrm{i}}=\mathrm{P}$ (sibs share $\mathrm{i}$ marker alleles IBD |DSP)

For $\mathrm{I}=0,1,2, \alpha_{i}$ equals $1 / 4,1 / 2$ and $1 / 4$ respectively. When a marker is unlinked, $Z_{i}=Y_{i}=\alpha_{i}$.

For ASPs the degree of deviation, $\delta_{i}$ that the probability of sharing IBD has from its null expectation is given by: ${ }^{40}$

$$
\delta_{\mathrm{i}}=\mathrm{Z}_{\mathrm{i}}-\alpha_{\mathrm{i}}
$$

Similarly the degree of deviation for DSPS, $\varepsilon_{i}$, is given by: ${ }^{40}$

$$
\varepsilon_{\mathrm{i}}=\mathrm{Y}_{\mathrm{i}}-\alpha_{\mathrm{i}}
$$

When $\theta=0$, the A SP probabilities are given by: ${ }^{40}$

$$
\begin{aligned}
& \mathrm{Z}_{0}=\alpha_{0}\left(1 / \lambda_{\mathrm{s}}\right) \\
& \mathrm{Z}_{1}=\alpha_{1}\left(\lambda_{0} / \lambda_{\mathrm{s}}\right) \\
& \mathrm{Z}_{2}=\alpha_{2}\left(\lambda_{\mathrm{m}} / \lambda_{\mathrm{s}}\right)
\end{aligned}
$$

and the DSP probabilities are given by: ${ }^{40}$

$$
\begin{aligned}
& Y_{s 0}=\alpha_{0}\left[(1-K) /\left(1-K_{s}\right)\right] \\
& Y_{s 1}=\alpha_{1}\left[\left(1-K_{o}\right) /\left(1-K_{s}\right)\right] \\
& Y_{s 2}=\alpha_{2}\left[\left(1-K_{m}\right) /\left(1-K_{s}\right)\right]
\end{aligned}
$$

$\lambda_{\mathrm{s}}=\mathrm{K}_{\mathrm{s}} / \mathrm{K}$ and $\lambda_{\mathrm{o}}=\mathrm{K}_{\mathrm{o}} / \mathrm{K}$ where $\mathrm{K}_{\mathrm{s}}$ and $\mathrm{K}_{\mathrm{o}}$ are the sibling and offspring recurrence risks respectively, and $\mathrm{K}$ is the population risk.

These formulae hold true irrespective of the mode of inheritance at the disease locus any number of alleles and their frequencies, penetrance and population prevalence. The only requirement is that recombination be negligible.

R isch ${ }^{40}$ showed that the A SP probabilities for a multiplicative model are identical to a single locus formulae except that $\lambda_{1 \mathrm{~s}}$ replaces $\lambda_{\mathrm{s}^{\prime}}$ H ence the DSP probabilities will be according specified. The formulae for the genetic heterogeneity model is well approximated by the additive model. The A SP probabilities for two unlinked loci given by $\mathrm{R}$ isch ${ }^{37}$ are:

$$
\begin{aligned}
& Z_{0}=\alpha_{0}-\alpha_{0}\left(K_{1} / K_{2}\right) \cdot 1 / \lambda_{s^{\prime}}\left(\lambda_{1 s}-1\right) \\
& Z_{1}=\alpha_{1}-\alpha_{1}\left(K_{1} / K_{2}\right) \cdot 1 / \lambda_{s^{\prime}}\left(\lambda_{10}-\lambda_{1 s}\right) \\
& Z_{2}=\alpha_{2}+\alpha_{2}\left(K_{1} / K_{2}\right) \cdot 1 / \lambda_{s^{\prime}}\left(\lambda_{1 m}-\lambda_{1 s}\right)
\end{aligned}
$$

where $\mathrm{K}=\mathrm{K}_{1}+\mathrm{K}_{2}$ and the overall sibling recurrence risk is given by: $:^{39}$

$$
\mathrm{KK}_{\mathrm{R}}=\mathrm{K}_{1} \mathrm{~K}_{1 \mathrm{R}}+\mathrm{K}_{2} \mathrm{~K}_{2 \mathrm{R}}+2 \mathrm{~K}_{1} \mathrm{~K}_{2}
$$

Through a conditional probability argument the D SP probabilities can be shown to be given by:

$$
\begin{aligned}
& Y_{0}=\alpha_{0}+a_{0} \cdot\left(K_{1} / K_{2}\right) \cdot K \cdot\left(\lambda_{1 s}-1\right) /\left(1-K_{S}\right) \\
& Y_{1}=\alpha_{1}-\alpha_{1} \cdot\left(K_{1} / K_{2}\right) \cdot K \cdot\left(\lambda_{10}-\lambda_{1 s}\right) /\left(1-K_{S}\right) \\
& Y_{2}=\alpha_{2}-\alpha_{2} \cdot\left(K_{1} / K_{2}\right) \cdot K \cdot\left(\lambda_{1 m}-\lambda_{1 s}\right) /\left(1-K_{S}\right)
\end{aligned}
$$

For both A SPs and D SPs the power to detect linkage depends on the total value of $\lambda$ and not solely on the $\lambda$ value at the one locus.

\section{Appendix 2. Power Calculations}

The maximum likelihood statistics for A SPs and D SPS are defined as the maximised likelihood ratio divided by the likelihood when $Z_{i}$ or $Y_{i}$ equals $\alpha_{i}$. U sing the A SP and DSP probabilities of sharing 0,1 and 2 alleles $I B D$, the number of affected sibling pairs who share 0 , 1 , or 2 alleles was simulated based upon these allele sharing probabilities for $\mathrm{N}$ sibling pairs. Incorporating the effect of recombination between the trait and the 
marker loci R isch ${ }^{40}$ showed that the A SPs probabilities are given by:

$$
\begin{aligned}
& \mathrm{Z}_{0}=\alpha_{0}-\alpha_{0}(2 \Psi-1) \cdot 1 / \lambda_{s} \cdot\left(\lambda_{s}-1\right) \\
& \mathrm{Z}_{1}=\alpha_{1}+\alpha_{1}(2 \Psi-1) \cdot 1 / \lambda_{s} \cdot\left(\lambda_{s}-\lambda_{0}\right) \\
& \mathrm{Z}_{2}=\alpha_{2}+\alpha_{2}(2 \Psi-1) \cdot 1 / \lambda_{s^{\prime}}\left(\lambda_{\mathrm{m}}-\lambda_{\mathrm{s}}\right)
\end{aligned}
$$

where the parameter $\Psi=\theta^{2}+(1-\theta)^{2}$ and $Y_{i}=$ $\alpha_{i}\left[1 /\left(1-K_{s}\right)\right]-Z_{i}\left[K_{s} /\left(1-K_{s}\right)\right]^{42}$

To reflect undertaking a genome-wide screen using markers spaced at $10 \mathrm{~cm}$ intervals, $\theta$ was set at 0.05 . For a range of $\mathrm{N}, 5000$ simulations were generated. The power was given by the percentage of simulations which exceeded a lod of 3.0. 